\title{
Activated Carbon-Limestone-Alginate Beads for the Simultaneous Removal of Color and Turbidity of Kerian River
}

\author{
Nurul Aini Zainol Abidin ${ }^{1}$, Puganeshwary Palaniandy ${ }^{1, *}$, Mohd Suffian Yusoff ${ }^{1}$, \\ Salem S. Abu Amr²
}

${ }^{1}$ School of Civil Engineering, Universiti Sains Malaysia, 14300 Pulau Pinang, MALAYSIA

${ }^{2}$ Malaysian Institute of Chemical and Bioengineering Technology, Universiti Kuala Lumpur, 78000 Melaka, MALAYSIA

*Corresponding Author

DOI: https://doi.org/10.30880/ijie.2019.11.01.004

Received 27 April 2018; Accepted 27 September 2018; Available online 05 May 2019

\begin{abstract}
Activated carbon-limestone-alginate bead (ALA) was synthesized for the adsorption of color and turbidity of river water. This adsorbent was characterized using Scanning Electron Microscopy (SEM) and Fourier transform infrared (FTIR) spectroscopy. Langmuir and Freundlich models were used for a mathematics description of the adsorption isotherm. The maximum adsorption capacity for color and turbidity obtained from Langmuir model were $0.446 \mathrm{PtCo} / \mathrm{g}$ and $5.155 \mathrm{NTU} / \mathrm{g}$ respectively. The equilibrium process was described well by the Freundlich isotherm model. Furthermore, the adsorption kinetics revealed that the adsorption process was successfully fitted with the pseudo-second-order kinetic model. All the results validated the feasibility of ALA for color and turbidity removal from river water.
\end{abstract}

Keywords: Adsorption, alginate, limestone, activated carbon, color, turbidity

\section{Introduction}

Water cannot be denied in human life as it gives a lot of benefits such as drinking, laundering, municipal and industrial development [1], [2]. However, the rapid growth of urban centers leads to the increased pollution of water sources. Unsafe water, poor sanitation and hygiene cause around 842,000 deaths each year [3]. The quality of river water has also undermined as rapid changes from contamination emanating from agricultural, industrial and natural activities. High turbidity can substantially reduce the aesthetic quality of lakes and streams, having a harmful impact on recreation and tourism. Meanwhile, the presence of color in water is unsuitable for dyeing, paper industry, beverages production and other food products [4].

Several methods of water treatment including coagulation [5], advanced oxidation process [6], ozonation [7], adsorption [8] and others have been effectively considered for the removal of various pollutants from water. All of them have advantages and disadvantages regarding their cost, environmental impact and productiveness [9]. Adsorption being the most significant separation technique that has wider application for the removal of organic and inorganic micropollutants from water due to its operation that easy to handle and large selection of adsorbents available [10]. 
Activated carbon is the most effective adsorbent applied for the removal of pollutants from aqueous or gaseous phase [11] owing to its high specific surface area, adsorption capacity and microporous structure. Nevertheless, the activated carbon is very expensive and has many problems with the regeneration [12]. Thus, low cost materials such as pine wood, rice husk, peat and coconut shell are used in order to solve this problem.

Limestone has been recognized as a good adsorbent because of its inexpensiveness and abundant in nature as it is widely available in Malaysia. It has been studied that limestones are able to remove heavy metal such as arsenic (III) and iron through filtration process [13]. Limestone also provides beneficial characteristics including heterogeneous surface, buffering quality, secondary binding site and repurposing [14]. Thus, it can be concluded that limestone has potential as low cost effective media in treating water.

Alginate is one of the most extensively investigated biopolymers for removal of pollutants from aqueous solution as it is inexpensive, efficient and non-toxic. It is a natural polysaccharide extracted from brown seaweeds [15]. Alginate is very important for textile and paper industries for developer on the surface of paper and clothing. Over $98 \%$ removal of turbidity was reported after using calcium alginate as coagulant in treating turbid water [16]. Furthermore, alginate is used in water treatment processes as a binder for composite media and flocculation process.

The single use of activated carbon, limestone, and alginate in water treatment is not always very promising; therefore, these three precursors were combined to make an effective composite material for color and turbidity removal. In this work, powdered activated carbon was used as an activated carbon, which was made from coconut shell. Thus, the objectives of this study were as follows: first, to prepare composite beads from the combination of activated carbon-limestone-alginate beads (ALA) via a simple production method; second, to identify the characteristics of the composite beads; lastly, to evaluate the best composite as an adsorbent for the removal of color and turbidity from Kerian River which located in the northern part of the Malaysian state of Perak. These two main parameters were selected as the physical characteristic that reflects the basic water quality parameters.

The Kerian River has a unique location that covers three states, Penang, Perak and Kedah. One of the usages of the Kerian River is for irrigation purpose. The sampling was carried out at this location due to short distance of this river to lab, which is around $10 \mathrm{~km}$ that takes around 10-15 minutes of driving.

\section{Material and Methods}

\subsection{River Water Sampling}

The sampling site is located at Lubok Buntar, Kedah $\left(5^{\circ} 7^{\prime} 37.60^{\prime \prime} \mathrm{N}, 100^{\circ} 35^{\prime} 42.97 " \mathrm{E}\right)$. Water samples were collected from Kerian River at Lubok Buntar. The samples were collected in Teflon containers (10 L per sample). According to the Standard Method of Water and Wastewater Examination, the samples were immediately transported to the USM Environmental Laboratory, School of Civil Engineering to preserve in a cold room at $4{ }^{\circ} \mathrm{C}$ prior to use so that the potential for contamination and volatilization of the samples can be minimized.

\subsection{Chemicals}

The coconut shell powdered activated carbon was obtained from Tan Meng Keong Sdn. Bhd., Selekoh, Perak; the particle size of the AC was -200 mesh. The limestone powder was obtained from a limestone quarry located in Batu Gajah, Perak. It was sieved with sieve aperture $150 \mu \mathrm{m}$ and retained $75 \mu \mathrm{m}$. Sodium alginate was purchased from R\&M Marketing Essex, UK and calcium chloride was supplied by Fisher Scientific UK. All other chemicals used in this work were of analytical grade. Distilled water was used for the preparation of all the required solutions.

\subsection{Preparation of ALA}

The adsorbents were prepared by mixing $2 \%(\mathrm{w} / \mathrm{v})$ sodium alginate, $3 \mathrm{~g}$ of activated carbon and $7 \mathrm{~g}$ of limestone in $100 \mathrm{~mL}$ of distilled water. The mixture was stirred with mechanical stirrer and heated to $80{ }^{\circ} \mathrm{C}$ on a hot plate. When the homogeneous condition between the mixture of activated carbon, limestone and alginate was reached, it was dropped through a syringe injector into $0.3 \mathrm{M}$ calcium chloride to form beads. The release beads were immersed in the calcium chloride solution for 12 hours in order to achieve hardened beads. The distilled water was used by washing the adsorbents many times to remove the excess unbounded calcium chloride from the adsorbent surface.

\subsection{Characterization of ALA}

The scanning electron microscope (SEM) micrographs of the adsorbents were obtained using Zeiss (Model Supra 35 VP, Germany). Fourier transform infrared spectroscopy (FTIR) analysis of the adsorbent before and after adsorption was carried out by using an FTIR spectroscopy (Perkin Elmer 2000, USA). The solid powder was mixed with KBr pellets and placed them in the infrared beam in the range of $4000-400 \mathrm{~cm}^{-1}$ for analysis. 


\subsection{Batch Adsorption Experiments}

Adsorption experiments were performed with $100 \mathrm{~mL}$ of river water sample in an array of $250 \mathrm{~mL}$ flasks. The amount of adsorbent was varied in the range of 1-23 $\mathrm{g}$ and the adsorbent was added to each flask. The flasks were shaken on an orbital shaker (Sartorious, Germany) at $130 \mathrm{rpm}$ until equilibrium was attained [17]. After that, the supernatant in the flasks was filtered (only for color parameter) at the end of the experiment and analyzed using DR2800 spectrophotometer at $\lambda_{\max }=455 \mathrm{~nm}$. Turbidity parameter was analyzed using TB400 turbidity meter. The removal efficiency $(R \%)$ and the amount of color and turbidity adsorbed onto ALA were calculated using the following equations:

$$
\begin{aligned}
& R=\frac{C_{0}-C_{e}}{C_{0}} \times 100 \\
& q_{e}=\frac{V}{M}\left(C_{0}-C_{e}\right)
\end{aligned}
$$

where $C_{o}$ and $C_{e}$ are the river water concentration at initial and equilibrium, respectively. $q_{e}$ is the adsorbed amount of color and turbidity per unit weight of adsorbent at a given time, $M$ is the mass of the adsorbent ( $\mathrm{g}$ ), $V$ is the volume of river water $(\mathrm{L})$.

\subsection{Adsorption Kinetics}

The pseudo-first-order and pseudo second-order models were used to analyze the adsorption kinetics for all parameters. This was done by shaking at the pre-determined shaking speed $(130 \mathrm{rpm})$ in $250 \mathrm{~mL}$ conical flasks containing $100 \mathrm{~mL}$ of river water sample and $17 \mathrm{~g}$ of optimum adsorbent dosage, which obtained from adsorption studies in Section 2.5. The samples were removed from the shaker after 5, 15, 30, 45, 60, 90, 120, 180, 360 minutes for analysis. The adsorption capacity, $q_{t}(\mathrm{PtCo} / \mathrm{g}$ or $\mathrm{NTU} / \mathrm{g})$ at different contact time $t$ (min) was determined using the following equation:

$$
q_{t}=\frac{\left(C_{o}-C_{t}\right) V}{M}
$$

where $C_{t}(\mathrm{PtCo} / \mathrm{L}$ or NTU/L) is the concentration of river water at time $t(\mathrm{~min})$ in the solution. All batch adsorption and kinetic experiments were repeated at least three times to ensure accuracy of the obtained data.

\section{Analytical Study}

Water samples were tested in the USM Environmental Laboratory in accordance with the Standard Methods for the Examination of Water and Wastewater [18]. The testing for color was done using spectrophotometer DR2800 with Method 2120-C. Turbidity measurement was tested according to Method 2130 using turbidity meter TB400.

\section{Results and Discussion}

\subsection{Characterization of Kerian River Water}

Table 1 shows the river water characterization with respect to the National Standard for Drinking Water Quality for Malaysia (NSDWQ). Parameters such as $\mathrm{pH}$ and temperature were determined by in situ analysis using YSI ProPlus Multiparameter. Other parameters such as COD and color were analyzed by using DR2800 in the laboratory, while turbidity was examined by turbidity meter, TB400 and E. coli was measured by using incubator MPN. Based on Water Quality Index (WQI) and Interim National Water Quality Standards for Malaysia (INWQS), Kerian River can be classified as Class II, which can be used as water supply and conventional treatment is required.

The turbidity of river water (77.02 NTU) was considered high and exceeded the NSDWQ of 5 NTU. Turbidity in river water is due to particles suspended or dissolved in water that scatter light making the water appear cloudy. Particulate matter can include sediment, especially clay and silt, fine organic and inorganic matter, coloring matter, algae, decaying animal and other microscopic organisms. Generally, colloids are the main factor of turbidity; however high turbidity during high rainfall in Taiwan is caused by clay, silt and suspended matters by influence of rainfall, erosion of upstream and re-rolling sediment in stream [19].

Color of water is very important in affecting consumer assurance towards the drinking water quality. The study reported that color observed having a yellowish appearance with concentration from 14 to 119 PtCo. The NSDWQ has stated the acceptable value of color is $15 \mathrm{PtCo}$. Ordinarily, natural organic matter (NOM) is comprised of suspended and dissolved matter. These particles can disseminate color into water. In addition, the removal of NOM is essential as 
the constituents that comprise dissolved NOM may lead to the formation of disinfection by-products (DBP) when chlorine is used for disinfection. NOM is also able to spread color to the water [20].

Table 2 shows the removal efficiency of color and turbidity using ALA in batch adsorption experiment. It consists of initial and final concentration of color and turbidity of river water.

Table 1 Characteristics of Kerian River water

\begin{tabular}{cccc}
\hline Parameter & Unit & Kerian River water & $\begin{array}{c}\text { Malaysia National Guidelines for } \\
\text { Drinking Water Quality }\end{array}$ \\
\cline { 3 - 3 } & & Average & - \\
Temperature & ${ }^{\circ} \mathrm{C}$ & 28.93 & $6.5-9.0$ \\
pH & - & 7.62 & 5 \\
Turbidity & NTU & 77.02 & 15 \\
Color & PtCo & 21.5 & - \\
COD & mg/L & 12.33 & 0 in $100 \mathrm{ml}$ \\
E. coli & MPN & 1204.73 & \\
\hline
\end{tabular}

Table 2 - Removal efficiency of color and turbidity by ALA in batch adsorption experiment

\begin{tabular}{lccc}
\hline \multicolumn{1}{c}{ Parameter } & $\begin{array}{c}\text { Initial Concentration } \\
\left(\mathbf{C}_{\mathbf{0}}\right)\end{array}$ & $\begin{array}{c}\text { Final Concentration } \\
\left(\mathbf{C}_{\mathbf{e}}\right)\end{array}$ & $\begin{array}{c}\text { Removal Efficiency } \\
(\mathbf{R} \%)\end{array}$ \\
\hline Color (PtCo) & 29 & 0 & 100 \\
Turbidity (NTU) & 230 & 23 & 90 \\
\hline
\end{tabular}

\subsection{ALA Characterization}

The adsorption of color and turbidity were verified by SEM analysis. SEM images were taken at 1000× (Fig. 1(a) and Fig. 1(b)) magnifications to observe the surface morphology of ALA as shown in Fig. 1. The surface morphologies of Fig. 1 (a) depicted that activated carbon and limestone were well attached together in the beads. More pores were observed in Fig. 1 (a) than in Fig. 1 (b) indicating that the bead has enough space for the adsorption process to take place. Based on Fig. 1 (b), less pores presented due to the flakes that covered the bead. Previous study on activated carbon-limestone-alginate composite also depicted the same images [21].
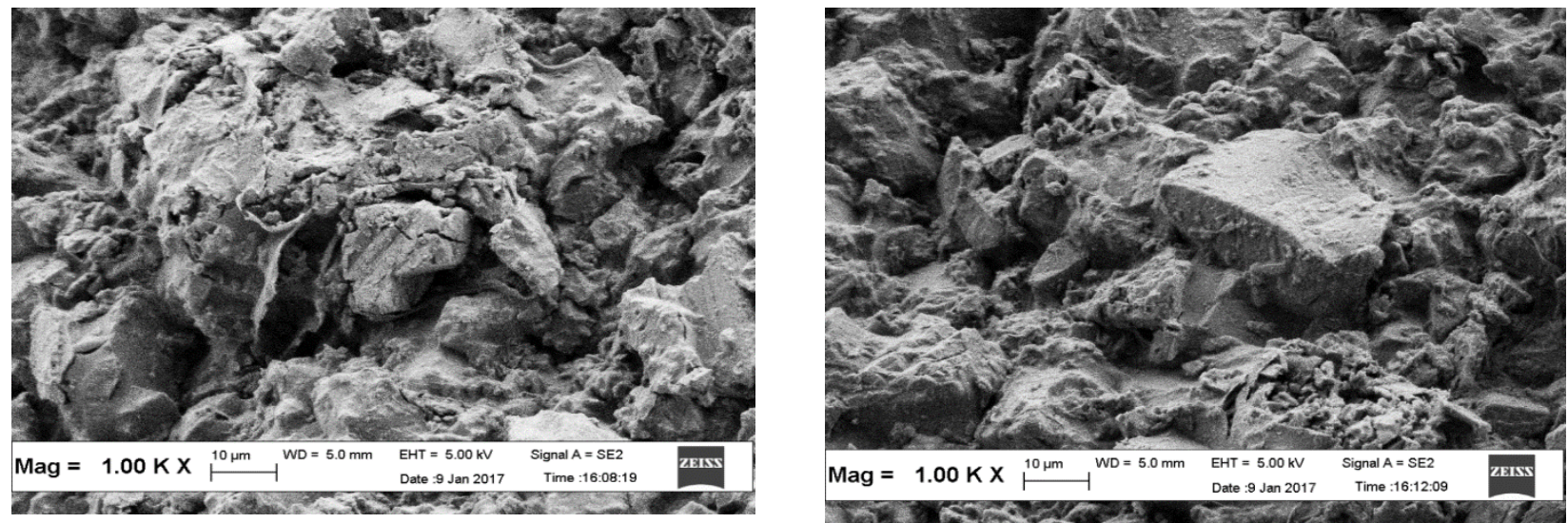

Fig. 1 - SEM image of ALA (a) before and (b) after adsorption

The FTIR spectra of ALA before and after adsorption are shown in Fig. 2 and Fig. 3. The phenolic group is found by the wide band at approximately $3394 \mathrm{~cm}^{-1}$ correlate with $\mathrm{O}-\mathrm{H}$ (hydroxyl) groups and that at $2514 \mathrm{~cm}^{-1}$ is responsible for the acid $\mathrm{O}-\mathrm{H}$ [17]. The peak at $712 \mathrm{~cm}^{-1}$ is ascribed to $\mathrm{C}-\mathrm{H}$ out of plane bending in benzene derivatives, which were found on the surface of activated carbons [22].

Many functional groups changed to different bands or disappeared after the adsorption. The band at $3394 \mathrm{~cm}^{-1}$ and $875 \mathrm{~cm}^{-1}$ shifted to higher frequencies at $3427 \mathrm{~cm}^{-1}$ and $876 \mathrm{~cm}^{-1}$ respectively. On the contrary, the peak at $2514 \mathrm{~cm}^{-1}$ and $1797 \mathrm{~cm}^{-1}$ disappeared after adsorption. 


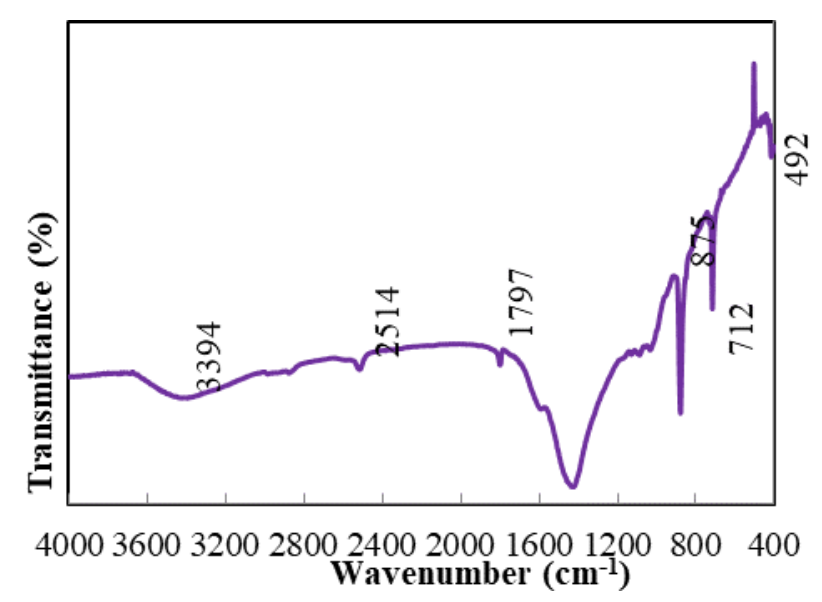

Fig. 2 - The FTIR spectrum of ALA before adsorption

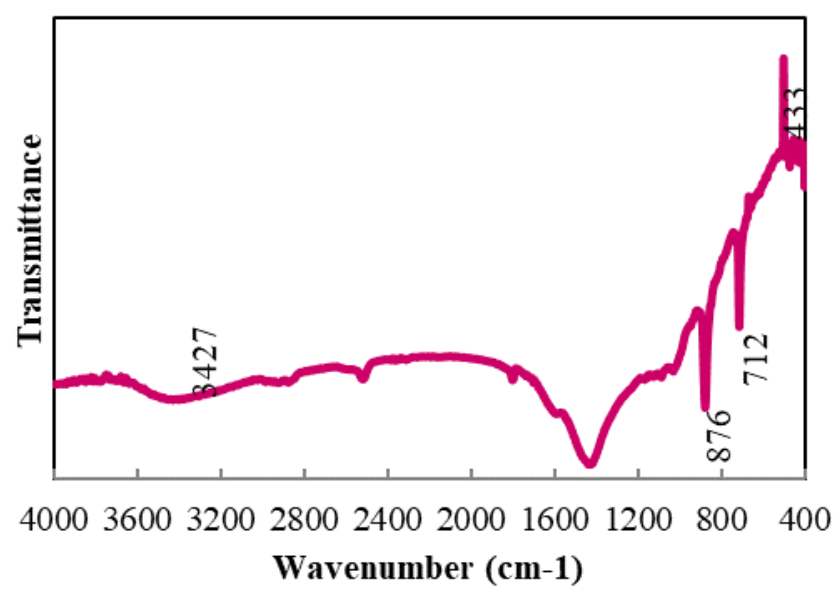

Fig. 3 - The FTIR spectrum of ALA after adsorption.

\subsection{Adsorption Isotherm}

Adsorption isotherm is crucial in explaining the equilibrium relationship between concentration in the fluid phase and the concentration in the adsorbent particles. In this study, Langmuir and Freundlich isotherms models were used to determine the color and turbidity adsorption isotherm parameters on the composite adsorbent. The experimental results were analysed using Langmuir and Freundlich models, which are expressed as the following equations, respectively [17]:

$$
\begin{gathered}
q_{e}=\frac{q_{m} K_{L} C_{e}}{1+K_{L} C_{e}} \\
q_{e}=K_{F} C_{e}^{\frac{1}{n}}
\end{gathered}
$$

where $q_{e}$ is the adsorbed amounts of color and turbidity per unit weight of adsorbent (PtCo/g or NTU/g) at an equilibrium concentration of adsorbate in bulk solution $\left(C_{e}, \mathrm{PtCo} / \mathrm{L}\right.$ or NTU/L). $K_{L}$ and $K_{F}$ are the Langmuir and Freundlich constants, respectively. $q_{m}$ (PtCo/g or NTU/g) is the Langmuir maximum adsorption capacity and $n$ is the heterogeneity factor.

$R^{2}$ and $R M S E$ function values were used in evaluating the applicability of these two models. The highest $R^{2}$ and the lowest $R M S E$ values at studied parameters determine the ideal isotherm model followed by this study. The $R^{2}$ and $R M S E$ were obtained using the following equations, respectively [23]: 


$$
\begin{gathered}
R^{2}=\frac{1-\sum_{n=1}^{n}\left(q_{e, n}-q_{m, n}\right)^{2}}{\sum_{n=1}^{n}\left(q_{e, n}-\overline{q m, n)^{2}}\right.} \\
R M S E=\sqrt{\frac{1}{n-1} \sum_{n-1}^{n}\left(q_{e, n}-q_{m, n}\right)^{2}}
\end{gathered}
$$

where $q_{e}$ and $q_{m}$ are the adsorbed amount per unit weight of adsorbent at equilibrium and the calculated value at equilibrium from the model, respectively. $n$ is the number of observations.

The parameters of Langmuir and Freundlich such as $K_{L}, q_{m}, K_{F}$, and $n$ in conjunction with the $R^{2}$ and $R M S E$ values are shown in Table 3. It can be seen that the adsorption data of color and turbidity on ALA are better described by the Freundlich model than the Langmuir model due to the high $R^{2}$ and low RMSE values.

The Freundlich model represents the best fit of experimental data which confirm that the removal of color and turbidity on the surface of ALA may involve multilayer adsorption. This reveals the physisorption mechanism. In addition, the Freundlich heterogeneity factor $n$ was found to be greater than 1 for all studied parameters indicates a favorable adsorption process.

\begin{tabular}{|c|c|c|c|c|c|}
\hline Isotherms & & & ameters & & \\
\hline \multirow{4}{*}{ Langmuir } & \multirow{3}{*}{ Color } & $\begin{array}{c}q_{m} \\
(\mathrm{PtCo} / \mathrm{g})\end{array}$ & $\begin{array}{c}K_{L} \\
\text { (L/PtCo) }\end{array}$ & $R^{2}$ & $R M S E$ \\
\hline & & 0.446 & 0.940 & 0.961 & 3.133 \\
\hline & & $\begin{array}{c}q_{m} \\
(\mathrm{NTU} / \mathrm{g})\end{array}$ & $\begin{array}{c}K_{L} \\
\text { (L/NTU) }\end{array}$ & & \\
\hline & Turbidity & 5.155 & 0.0102 & 0.974 & 0.0194 \\
\hline \multirow{4}{*}{ Freundlich } & \multirow{3}{*}{ Color } & $\begin{array}{c}K_{F} \\
\left(\mathrm{PtCo} / \mathrm{g}(\mathrm{L} / \mathrm{PtCo})^{1 / \mathrm{n}}\right)\end{array}$ & $n$ & $R^{2}$ & $R M S E$ \\
\hline & & 0.197 & 3.2 & 0.986 & 0.0180 \\
\hline & & $\begin{array}{c}K_{F} \\
\left(\mathrm{NTU} / \mathrm{g}(\mathrm{L} / \mathrm{NTU})^{1 / \mathrm{n}}\right) \\
\end{array}$ & & & \\
\hline & Turbidity & 0.142 & 1.571 & 0.982 & 0.0137 \\
\hline
\end{tabular}

Table 3 - Langmuir and Freundlich isotherm parameters for the adsorption of color and turbidity onto ALA

\subsection{Adsorption Kinetic}

Initially, the color and turbidity concentration in the river water sample was high, and many active sites were present in the ALA. These occurrences elucidated the early rapid color and turbidity adsorption of the ALA. In the adsorption stage, the color and turbidity concentration in the river water sample decreased and the adsorption sites were gradually occupied by these pollutants. Subsequently, color and turbidity adsorption of the ALA beads gradually increased and achieved equilibrium after 45 minutes and 60 minutes respectively, which exceeded $90 \%$ of color and turbidity removal.

The kinetic data in this study were applied to pseudo first-order and pseudo second-order models. The kinetic equation of Lagergren's pseudo first-order [24] and pseudo second-order [25] is shown as below:

$$
\begin{gathered}
\log \left(q_{e}-q_{t}\right)=\frac{\log q_{e}-k_{1} t}{2.303} \\
\frac{t}{q_{t}}=\frac{1}{k_{2} q_{e}^{2}}+\frac{t}{q_{e}}
\end{gathered}
$$

where $q_{e}$ is the equilibrium adsorption capacity $\left(\mathrm{PtCo} / \mathrm{g}\right.$ or NTU/g), $q_{t}$ is the adsorption capacity at $t(\mathrm{PtCo} / \mathrm{g}$ or NTU/g), $k_{1}$ is the pseudo first-order kinetic rate constant $\left(\mathrm{min}^{-1}\right) ; k_{2}$ is the pseudo second-order kinetic constant (g/PtCo.min or g/NTU.min). The kinetic equation and adsorption data are listed in Table 4. According to Table 4 the adsorption kinetics of color and turbidity onto ALA is better described by the pseudo second-order kinetic model because of the high $R^{2}$ value than the pseudo first-order model. 
Table 4 - Kinetic non-linear models parameters for color and turbidity adsorption by ALA

\begin{tabular}{|c|c|c|c|c|c|}
\hline Kinetic & & \multicolumn{4}{|c|}{ Parameters } \\
\hline \multirow{4}{*}{ Pseudo- first- order } & \multirow{3}{*}{ Color } & $q_{e, \exp }(\mathrm{PtCo} / \mathrm{g})$ & $\begin{array}{c}q_{e, c a l} \\
(\mathrm{PtCo} / \mathrm{g})\end{array}$ & $\begin{array}{c}k_{1} \\
(1 / \mathrm{min}) \times 10^{-3}\end{array}$ & $R^{2}$ \\
\hline & & 0.2059 & 0.0297 & 4.606 & 0.4675 \\
\hline & & $q_{e, \exp }(\mathrm{NTU} / \mathrm{g})$ & $\begin{array}{c}q_{e}, \mathrm{cal} \\
(\mathrm{NTU} / \mathrm{g})\end{array}$ & & \\
\hline & Turbidity & 0.4772 & 0.0183 & 6.2181 & 0.1437 \\
\hline \multirow{4}{*}{ Pseudo- second- order } & \multirow{3}{*}{ Color } & $q_{e, \exp }(\mathrm{PtCo} / \mathrm{g})$ & $\begin{array}{c}q_{e, c a l} \\
(\mathrm{PtCo} / \mathrm{g})\end{array}$ & $\begin{array}{c}k_{2} \\
(\mathrm{~g} / \mathrm{PtCo} . \mathrm{min})\end{array}$ & $R^{2}$ \\
\hline & & 0.2059 & 0.1897 & 10.67 & 0.9996 \\
\hline & & $q_{e, \exp }(\mathrm{NTU} / \mathrm{g})$ & $\begin{array}{c}K_{F} \\
\left(\mathrm{NTU} / \mathrm{g}(\mathrm{L} / \mathrm{NTU})^{1 / \mathrm{n}}\right)\end{array}$ & $\begin{array}{c}k_{2} \\
(\mathrm{~g} / \text { NTU.min }) \\
\end{array}$ & \\
\hline & Turbidity & 0.4772 & 0.4690 & 8.48 & 0.9999 \\
\hline
\end{tabular}

\section{Summary}

In this work, ALA was synthesized for adsorption of color and turbidity from river water. The synthesized beads were characterized using FTIR and SEM and basic performance data, including adsorption isotherms and adsorption kinetics, were collected. It was found that Langmuir and Freundlich model fit the experimental data well, but Freundlich isotherm was better according to error functions. In addition, pseudo second-order model fits the experimental data suitably well. Consequently, ALA may possibly be employed as an efficient adsorbent for the removal of color and turbidity from river water.

\section{Acknowledgement}

The authors would like to acknowledge the Ministry of Higher Education Malaysia for providing LRGS Grant on Water Security entitled Protection of Drinking Water: Source Abstraction and Treatment (203/PKT/6720006).

\section{References}

[1] Islam, M. H., Rahman, M. and Ashraf, F. U. (2010). Assessment of water quality and impact of effluents from fertilizer factories to the Lakhya River. International Journal of Water Resources and Environmental, 2, $208-221$.

[2] Afroz, R., Masud, M. M., Akhtar, R. and Duasa, J. B. (2014). Water Pollution: Challenges and Future Direction for Water Resource Management Policies in Malaysia. Environment and Urbanization Asia, 5, 63-81.

[3] World Health Organization. (2014). Preventing diarrhoea through better water, sanitation and hygiene. Geneva: World Health Organization.

[4] Malakootian M. and Fatehizadeh, A. (2010). Color removal from water by coagulation/ caustic. Iranian Journal of Environmental Health Science and Engineering, 7, 267-272.

[5] Ramavandi, B. (2014). Treatment of water turbidity and bacteria by using a coagulant extracted from Plantago ovata. Water Resources and Industry, 6, 36-50.

[6] Fahmi, M. R., Zulzikrami, C., Abidin, A., and Rahmat, N. R. (2011). Characteristic of color and COD removal of azo dye by advanced oxidation process and biological treatment. International Conference on Biotechnology and Environment Management, IACSIT Press, 18, 13-18.

[7] Akbar, N. A., Aziz, H. A. and Adlan, M. N. (2015). Potential use of ozonation with limestone adsorption in ground treatment: A case study at Kelantan water treatment plant. Jurnal Teknologi, 11, 43-50.

[8] Agnihotri S. and Singhal, R. (2017), Synthesis and characterization of novel poly (acrylic acid/sodium alginate/sodium humate) superabsorbent hydrogels. Part II: The effect of $\mathrm{SH}$ variation on $\mathrm{Cu} 2+, \mathrm{Pb} 2+, \mathrm{Fe} 2+$ metal Ions, MB, CV dye adsorption study. Journal of Polymers and the Environment, 26, 383-395.

[9] Chibban, M., Zerbet, M., Carja, G. and Sinan, F. (2012). Application of low-cost adsorbents for arsenic removal: A review. Journal of Environmental Chemistry and Ecotoxicology, 4, 91-102.

[10] Mohammed, M. A., Shitu, A. and Ibrahim, A. (2014), Removal of methylene blue using low cost adsorbent : A Review. Research Journal of Chemical Sciences, 4, 91-102.

[11] Halim, A. A., Aziz, H. A., Johari, M. A. M., Ariffin, K. S. and Adlan, M. N. (2010). Ammoniacal nitrogen and COD removal from semi-aerobic landfill leachate using a composite adsorbent: Fixed bed column adsorption performance. Journal of Hazardous Materials, 175, 960-964.

[12] Thomas, B. N., and George, S. C. (2015). Production of Activated Carbon from Natural Sources. iMedPub Journals, 1, 1-5.

[13]Devi, R. R., Umlong, I. M., Das, B., Borah, K., Thakur, A. J., Raul, P. K., Banerjee, S. and Singh, L. (2014). 
Removal of iron and arsenic (III) from drinking water using iron oxide-coated sand and limestone. Applied Water Science, 4, 175-182.

[14] Varajic, B. (2011). effective and affordable novel arsenic removal technology, Capstone Experience/Thesis Projects Western Kentucky University.

[15]Eldin, M. S. M., Soliman, E. A., Elzatahry, A. A. F., Elaassar, M. R., Elkady, M. F., Rahman, A. M. A., Yossef, M. E. and Eweida, B. Y. (2012). Preparation and characterization of imino diacetic acid functionalized alginate beads for removal of contaminants from waste water: I. methylene blue cationic dye model. Desalination and Water Treatment, 40, 15-23.

[16]Devrimci, H. A., Yuksel, A. M. and Sanin, F. D. (2012). Algal alginate: A potential coagulant for drinking water treatment. Desalination, 299, 16-21.

[17] Benhouria, A., Islam, M. A., Zaghouane-Boudiaf, H., Boutahala, M. and Hameed, B. H. (2015). Calcium alginatebentonite-activated carbon composite beads as highly effective adsorbent for methylene blue. Chemical Engineering Journal, 270, 621-630.

[18]APHA. (2005). Standard methods for the examination of water and wastewater (19th Edition). Washington: American Public Health Association.

[19]Lee, C. S., Lee, Y. C. and Chiang, H. M. (2016).Abrupt state change of river water quality (turbidity): Effect of extreme rainfalls and typhoons. Science of the Total Environment, 557, 91-101.

[20] Howe, K. J., Hand, D. W., Crittenden, J. C., Trussell, R. R. and Tchobanoglous, G. (2012). Principles of water treatment (Volume 1). New Jersey: John Wiley and Sons.

[21] Kamaruddin, M. A. (2015). Development of carbon mineral composite adsorbent, PhD Thesis. Universiti Sains Malaysia.

[22] Hameed, B. H., Salman, J. M. and Ahmad, A. L. (2009). Adsorption isotherm and kinetic modeling of 2,4-D pesticide on activated carbon derived from date stones. Journal of Hazardous Materials, 163, 121-126.

[23] Jung, K. W., Choi, B. H., Hwang, M. J., Jeong, T. U. and Ahn, K. H. (2016). Fabrication of granular activated carbons derived from spent coffee grounds by entrapment in calcium alginate beads for adsorption of acid orange 7 and methylene blue. Bioresource Technology, 219, 185-195.

[24] Hussain, S., Aziz, H. A., Isa, M. H., Adlan, M. N. and Asaari, F. A. H. (2006). Physico-chemical method for ammonia removal from synthetic wastewater using limestone and GAC in batch and column studies. Bioresource Technology, 98, 874-880.

[25] Jing, C., Cui, J., Huang, Y. and Li, A. (2012). Fabrication, characterization, and application of a composite adsorbent for simultaneous removal of arsenic and fluoride. ACS Applied Materials and Interfaces, 4, 714-20. 